Rabaska

Revue d'ethnologie de l'Amérique française

\title{
Le Centre de conservation du Québec (Ministère de la Culture et des communications)
}

\section{Patrick Albert}

Volume 17, 2019

URI : https://id.erudit.org/iderudit/1066052ar

DOI : https://doi.org/10.7202/1066052ar

Aller au sommaire du numéro

Éditeur(s)

Société québécoise d'ethnologie

ISSN

1703-7433 (imprimé)

1916-7350 (numérique)

Découvrir la revue

Citer ce document

Albert, P. (2019). Le Centre de conservation du Québec (Ministère de la Culture et des communications). Rabaska, 17, 391-392.

https://doi.org/10.7202/1066052ar d'utilisation que vous pouvez consulter en ligne. 
Le Musée est très présent dans la communauté. Il rejoint les plus jeunes par son programme scolaire virtuel et est partenaire d'événements tels la Biennale de sculpture ou la Fête des chants de marins. Il est devenu une destination culturelle pour la population régionale et les touristes désireux de vivre une expérience muséale différente.

Judith DouviLle

\section{Le Centre de conservation du Québec}

Ministère de la Culture et des communications 1825 , rue Semple

Québec (Québec)

G1N 4B7

Téléphone : (418) 643-7001

Courriel : ccq@mcc.gouv.qc.ca

Toile : www.ccq.gouv.qc.ca

Le $1^{\text {er }}$ avril 2019 marquait le $40^{\text {e }}$ anniversaire de la création du Centre de conservation du Québec. C'est en effet en 1979 que le ministère des Affaires culturelles de l'époque rassemblait un premier groupe de trois restaurateurs de biens culturels et leur adjoignait un directeur, une secrétaire et un photographe pour entamer un périple qui serait des plus bénéfiques pour la conservation du patrimoine québécois. Aujourd'hui, l'équipe du CCQ regroupe plus d'une quarantaine de personnes, dont une trentaine de restauratrices et restaurateurs professionnels.

\section{Réalisations du personnel du CCQ}

Au cours de la dernière année, les réalisations du personnel du Centre ont été nombreuses :

- Production de plus de 25400 heures de services de restauration, d'expertise ou de formation, dont plus de 15200 ont été financées par le ministère de la Culture et des communications, et près de 10200 ont été facturés aux clientèles.

- Participation au sauvetage du rempart palissadé de Beaucours, mis au jour à l'automne 2018 lors de travaux de construction dans le Vieux-Québec. L'expertise des restaurateurs du CCQ a été essentielle pour que l'extraction des vestiges soit faite dans les règles de l'art afin de pouvoir les mettre rapidement à l'abri du gel et entamer le traitement qui permettra leur conservation et leur éventuelle mise en valeur. - Préparation d'un Plan d'intervention en cas de sinistre par deux restauratrices du CCQ, en collaboration avec des professionnels du ministère de la Culture et des communications. Il sera diffusé aux clientèles cibles au cours de l'exercice financier 2019-2020 afin de les aider à mieux se préparer s'ils devaient subir un sinistre et à poser les bons gestes pour protéger leurs biens patrimoniaux lorsque ce risque se matérialise.

- Finalisation de la rédaction d'une synthèse des travaux de restauration des artéfacts extraits de l'épave du Elizabeth \& Mary. Elle présentera plus de 25 ans de travaux ayant permis de conserver et de mettre en valeur des centaines d'objets qui nous aident à mieux comprendre le contexte historique de l'attaque de Phipps sur Québec en 1690. Cette synthèse devrait être publiée au cours de l'année 2020. 


\section{Célébration du $40^{e}$ anniversaire $d u C C Q$}

L'année 2019-2020 sera marquée par une série de petits événements et d'initiatives de communication pour marquer le $40^{\circ}$ anniversaire du CcQ, tous ayant comme objectif de mieux faire connaître l'ampleur et la valeur de l'expertise du personnel du CCQ. On veut ainsi démontrer comment le recours à cette mine d'expertise peut contribuer à mettre en valeur tous types de biens patrimoniaux au bénéfice de la population, des propriétaires et des communautés qui en ont la garde.

Ainsi, le CCQ :

- a participé aux assises annuelles de l'Union des municipalités du Québec afin d'y rencontrer des intervenants municipaux ayant la garde de biens patrimoniaux et de leur faire connaître les services que le CCQ peut leur rendre;

- a participé aux Rendez-vous Maestria, événement organisé par le Conseil des métiers d'art du Québec, afin de faire connaître les services du CCQ aux artisans et professionnels œuvrant dans le secteur du bâtiment et de la restauration architecturale; - a collaboré avec la Direction des communications et des affaires publiques du McC afin de réaliser une série de capsules vidéo présentant des réalisations marquantes du personnel du CCQ et pour augmenter la présence de l'organisation dans les médias sociaux par la publication de nouvelles brèves mises en lien avec le site Web du Centre;

- a travaillé en collaboration avec la Direction générale du patrimoine et les Directions régionales du Mcc dans la réalisation de leurs mandats respectifs en matière de conservation et de restauration d'œuvres et d'objets de patrimoine.

\section{Expertises sur des biens culturels}

La dernière année a aussi été remarquable par la réalisation d'un grand nombre d'expertises sur des biens religieux, des collections d'art public ou des éléments architecturaux. Ceci augure d'une prochaine année bien remplie au cours de laquelle l'expertise du personnel du CCQ continuera de rayonner et de rapporter des dividendes tangibles pour l'ensemble des citoyens et pour tous les propriétaires et gardiens de biens patrimoniaux.

PATRick Albert

\section{Laboratoire d'enquête ethnologique et de multimédia (LEEM)}

2256, Pavillon Charles-De-Koninck

Université Laval

1030, avenue des Sciences humaines

Québec (Québec)

G1V 0A6

Téléphone : (418) 656-2131,p. 403111 Courriel : Laurier.Turgeon@hst.ulaval.ca Toile : www.leem.ulaval.ca

L'année 2018-2019 fut pour la Laboratoire d'enquête ethnologique et de multimédia (LEEM) une année riche en projets et en expériences variées, tant en recherche fondamentale qu'en recherche appliquée. 